\title{
Perception and Use of Compensation Strategies for Gait Impairment by Persons With Parkinson Disease
}

Anouk Tosserams, MD, Lisanne Wit, BSc, Ingrid H.W.M. Sturkenboom, PhD, Maarten J. Nijkrake, PT PhD, Bastiaan R. Bloem, MD PhD, and Jorik Nonnekes, MD PhD

Neurology ${ }^{\circledR}$ 2021;97:e1404-e1412. doi:10.1212/WNL.0000000000012633

\author{
Correspondence \\ Dr. Tosserams \\ anouk.tosserams@ \\ radboudumc.nl

\section{MORE ONLINE} \\ (II) Class of Evidence \\ Criteria for rating \\ therapeutic and diagnostic \\ studies \\ NPub.org/coe
}

\section{Methods}

A survey was conducted among 4,324 adults with PD and self-reported disabling gait impairments.

\section{Results}

The main findings are as follows: (1) compensation strategies for gait impairments are commonly used by persons with PD, but their awareness of the full spectrum of available strategies is limited; (2) the patient-rated efficacy of compensation strategies is high but varies depending on the context in which they are applied; and (3) compensation strategies are useful for all types of patients with PD, but the efficacy of the different strategies varies per person.

\section{Discussion}

The choice of compensation strategies for gait impairment in PD should be tailored to the individual patient and to the context in which the strategy needs to be applied.

\section{Classification of Evidence}

This data provides Class IV evidence that compensation strategies are an effective treatment for gait impairment in patients with PD. 


\section{Glossary}

FOG = freezing of gait; PD = Parkinson disease.

Gait impairments are common and are reckoned among the most disabling symptoms of Parkinson disease (PD). They often give rise to falls and fall-related injuries and decreased functional mobility, independence, and quality of life. ${ }^{1-3}$ Gait disturbances in PD can be continuously present (i.e., smaller step length, slower gait speed, or higher gait variability) or, as the disease progresses, become more episodic in nature (e.g., bouts of festination or freezing of gait [FOG] $)^{4,5}$ Episodic gait deficits such as FOG may occur when the patient initiates gait, turns, or attempts to cross a narrow space (e.g., passing a doorway); when the patient is anxious; or when the patient performs a concurrent task while walking (e.g., talking or carrying a tray). ${ }^{6-8}$

Dopaminergic treatment alone is seldomly satisfactory in ameliorating these disabling gait impairments, especially with increasing disease duration. ${ }^{9,10}$ Remarkably, patients often spontaneously invent creative "detours" to overcome their walking difficulties in order to remain mobile and independent. These so-called compensation strategies can be very diverse; examples include walking paced by the rhythm of a metronome or by imaginary counting, mimicking the gait of another person, resorting to an adapted walking pattern (e.g., walking backward, lifting the knees up high), or using alternative ways to move forward such as roller skating. A wide range of different compensation strategies has been reported, typically in the form of anecdotal case reports, describing a typically self-invented solution that apparently worked very well for that particular individual. ${ }^{11-13}$ Recently, a comprehensive overview of compensation strategies to overcome gait impairments was published in which a conceptual framework of 7 separate overarching categories of compensation strategies was proposed based on their suspected underlying working mechanisms (Table 1). ${ }^{14}$

Clinical observations suggest that a certain compensation strategy may be highly effective in one person but may have no effect on or even aggravate gait disability in another person. Furthermore, even within one individual, a specific strategy may have different effects depending on the context in which it is applied (e.g., when preparing food in the kitchen vs when walking outside). ${ }^{15-17}$ To date, this has not been systematically investigated, hampering the ability of health care professionals to provide a more tailored, personalized approach to gait rehabilitation for persons with PD. Consequently, in current daily practice, the search for appropriate compensation strategies for a given person with $\mathrm{PD}$ remains a time-consuming trial-anderror process. Moreover, individual patients are rarely offered an opportunity to systematically try out the multiple different variants of compensation strategies until they find a specific one that suits their needs and abilities best.
To address this issue, we conducted an international webbased survey among persons with PD experiencing gait impairments. The aim of this study was 3-fold: (1) to evaluate the participants' awareness and use of the various compensation categories for gait impairments in PD, (2) to investigate the patient-rated efficacy of compensation strategies and whether this depends on the context in which the strategies are applied, and (3) to explore whether different patient subgroups (defined by sex, age, disease duration, freezing status, and ability to perform a dual task) might respond differently to certain types of compensation strategies.

\section{Methods}

\section{Study Design}

The primary research questions were as follows. (1) To what extent do participants know and use the 7 categories of compensation strategies for gait impairments in PD? (2) What is the patient-rated efficacy of compensation strategies, and does this differ depending on the context in which the strategies are applied? (3) Do different subgroups of participants (defined by sex, age, disease duration, freezing status, and ability to perform a dual task) respond differently to certain categories of compensation strategies (Class IV evidence)?

A web-based survey was distributed among 6,700 participants within the Fox Insight cohort, as well as 1,573 Dutch participants via ParkinsonNEXT (the Netherlands). Fox Insight is a longitudinal, virtual, patient-centered observational study on PD led by the Michael J. Fox Foundation. Data used in the preparation of this article were obtained from the Fox Insight database on June 1, 2020. For up-to-date information on the study, interested readers should visit the Fox Insight website. ParkinsonNEXT is an online platform that aims to unite patients, researchers, and clinicians wanting to contribute to research and innovation in PD or parkinsonism. The online survey was accessible from March to June 2020. Respondents $>18$ years of age with a self-reported diagnosis of PD and selfreported disabling gait impairments were included in the analyses.

The survey consisted of 3 parts (eAppendix 1, links.lww.com/ WNL/B492). The first part asked about sex, age, time since PD diagnosis, and the presence and severity of gait impairments. Moreover, the presence and severity of FOG were assessed with the New Freezing of Gait Questionnaire. ${ }^{18}$ They were also asked about their fall history over the preceding 12 months. The second part of the survey addressed the 7 main categories of compensation strategies (Table 1). ${ }^{14}$ 
Table 1 Proposed Categorization of Compensation Strategies ${ }^{14}$

\begin{tabular}{|c|c|c|}
\hline Compensation category & Description & Phenomenology ${ }^{a}$ \\
\hline External cueing & $\begin{array}{l}\text { Typically rhythmic external stimuli that may be auditory, } \\
\text { somatosensory, or visual }\end{array}$ & $\begin{array}{l}\text { Walking to the beat of a metronome; wearing vibrating } \\
\text { socks; stepping over lines }\end{array}$ \\
\hline Internal cueing & Focusing attention on (predetermined components of) gait & Self-prompting; mental arithmetic \\
\hline $\begin{array}{l}\text { Changing the balance } \\
\text { requirements }\end{array}$ & Facilitating the ability to make lateral weight shifts & $\begin{array}{l}\text { Shifting weight in place before stepping; making wider } \\
\text { turns; using walking aids }\end{array}$ \\
\hline Altering the mental state & $\begin{array}{l}\text { Enhancing general alertness and arousal, leading to } \\
\text { increased motivation or relaxation }\end{array}$ & $\begin{array}{l}\text { Breathing exercises; other measures to limit anxiety or } \\
\text { fear of falling }\end{array}$ \\
\hline $\begin{array}{l}\text { Action observation and motor } \\
\text { imagery }\end{array}$ & NA & $\begin{array}{l}\text { Mimicking another person walking; visualizing the } \\
\text { desired movement }\end{array}$ \\
\hline Adapting a new walking pattern & $\begin{array}{l}\text { Changing the straight gait pattern or using other forms of } \\
\text { locomotion }\end{array}$ & $\begin{array}{l}\text { Scissoring; knee lifting; jumping; running; walking } \\
\text { backward }\end{array}$ \\
\hline $\begin{array}{l}\text { Other forms of using the legs to } \\
\text { move forward }\end{array}$ & NA & Bicycling; skateboarding; crawling \\
\hline
\end{tabular}

Abbreviation: $\mathrm{NA}=$ not applicable.

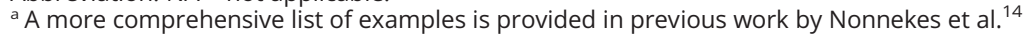

One by one, each specific category was explained and illustrated by several practical examples. Participants were then queried whether they were aware of the category of strategies, whether they had ever applied a strategy belonging to that category, and, if so, how application of this strategy had affected their gait in a variety of contexts. These contexts included gait initiation, turning, stopping, passing a doorway, walking in narrow spaces, walking outdoors, walking in a crowded area, walking while talking, walking while carrying something, performing activities of daily living, and timepressure situations. Respondents could indicate whether applying the strategy in that specific context improved their gait, had no effect on their gait, or worsened their gait. The third part of the survey examined the participants' interest to learn more about compensation strategies for gait impairments in $\mathrm{PD}$. At the end of the survey, respondents were given an openended opportunity to share any new compensation strategies other than the ones already presented in the overview. In all cases, the mentioned strategies fitted into 1 of the 7 proposed categories and were therefore migrated to the corresponding categories.

For Fox Insight respondents, data from a preexisting Fox Insight questionnaire, Your Cognition and Daily Activities, were also included in the analyses. No data on cognition were available for respondents from the ParkinsonNEXT cohort.

\section{Data Processing and Analysis}

According to the free-text entries that respondents had provided, data were verified and manually corrected by 2 independent researchers (A.T., L.W.) to ensure that all recorded compensation strategies were completed under the appropriate corresponding category. All (descriptive) statistical analyses were performed in IBM SPSS 25 (SPSS, Inc, Chicago, IL). Any missing values were excluded from the analyses. Independent $t$ tests (means) and $\chi^{2}$ tests (proportions) were performed to assess subgroup differences. Values of $p<0.05$ were considered to be statistically significant.

\section{Standard Protocol Approvals, Registrations, and Patient Consents}

The study was approved by the Institutional Review Board of the Radboud University Medical Center in Nijmegen, the Netherlands (reference: 2019-5737). Written informed consent was not necessary for this work.

\section{Data Availability}

Data are available to qualified investigators on request to the corresponding author.

\section{Results}

\section{Study Population}

In total, 4,987 responses were collected via Fox Insight (response rate $74.4 \%$ ) and 845 via ParkinsonNEXT (response rate $53.7 \%$ ). The 1,508 persons who did not report disabling gait impairments were excluded. Characteristics of the included sample of 4,324 respondents are presented in Table 2 . Differences in the main characteristics of responders vs nonresponders from the ParkinsonNEXT cohort were not clinically relevant in terms of sex distribution ( $62.1 \%$ vs $64.6 \%$ men), age (66.4 years vs 64.5 years), and disease duration ( 6.5 years vs 5.9 years since diagnosis). These data were not available for the Fox Insight sample.

Of the 4,324 persons with gait impairments who were included, 35.3\% found that their walking difficulties negatively affected their ability to perform their usual daily activities. Of note, $52.4 \%$ of respondents had experienced $\geq 1$ falls in the 
Table 2 Characteristics of Included Respondents

\begin{tabular}{lllll}
\hline & Total cohort & Fox Insight & ParkinsonNEXT (NL) & $\boldsymbol{p}$ Value \\
\hline Respondents, $\mathbf{n}$ & 4,324 & 3,663 & 661 & $427(64.6)$ \\
\hline Men, $\mathbf{n}(\%)$ & $2,387(55.3)$ & $1,960(53.6)$ & $66.4 \pm 8.6$ & $<0.001^{\text {a }}$ \\
\hline Age, $\mathbf{y}$ & $67.8 \pm 9.0$ & $68.0 \pm 9.0$ & $6.5 \pm 4.6$ & $<0.001^{\text {a }}$ \\
\hline Time since diagnosis, $\mathbf{y}$ & $6.7 \pm 5.3$ & $6.7 \pm 5.4$ & $199(30.1)$ & 0.51 \\
\hline Respondents with FOG, (n (\%) & $1,851(42.8)$ & $1,652(45.1)$ & $17(5-28)$ & $<0.001^{\text {a }}$ \\
\hline NFOG-Q score, ${ }^{\mathbf{b}}$ median (range) & $17(1-28)$ & $17(1-24)$ & $0.03^{\text {a }}$
\end{tabular}

Abbreviations: FOG = freezing of gait; NFOG-Q = New Freezing of Gait Questionnaire (score range $0-28$ ); NL = the Netherlands. ${ }^{18}$

Values are represented as mean \pm SD unless otherwise specified.

a Statistically significant difference between Fox Insight cohort and ParkinsonNEXT cohort as determined by independent-samples $t$ test (means) or $\chi^{2}$ test (proportions).

${ }^{\mathrm{b}}$ Among respondents with FOG, defined by a nonzero NFOG-Q score.

preceding 12 months, resulting in injury that had required medical attention in 385 cases.

Data from the Fox Insight questionnaire Your Cognition and Daily Activities were available for 3,586 of 3,663 (97.9\%) respondents from the Fox Insight cohort enrolled in the present study. The majority of these respondents had little to no difficulties performing cognitive tasks in daily life. Specifically, most respondents had little to no difficulties reading the newspaper or a magazine (88.7\%); keeping track of time (e.g., using a clock) (96.1\%); counting the correct amount of money when making purchases $(96.8 \%)$; reading or following complex instructions (e.g., directions for a new medication) (90.9\%); handling an unfamiliar problem (e.g., getting the refrigerator fixed) (88.0\%); explaining how to do something involving several steps to another person $(84.0 \%)$; remembering a list of 4 or 5 errands without writing it down (69.1\%); using a map to tell where to go $(92.1 \%)$; remembering new information such as phone numbers or simple instructions $(77.2 \%)$; doing $>1$ thing at a time $(76.0 \%)$; learning to use new gadgets or machines around the house (84.2\%); understanding their personal financial affairs (92.5\%); maintaining or completing a train of thought (92.5\%); discussing a TV show, a book, a movie, or current events (88.5\%); or remembering what day and month it is (93.8\%). Fewer than $1 \%$ of respondents indicated that they were completely incapable of performing $\geq 1$ of these daily activities.

\section{Awareness of Compensation Strategies}

Of all respondents, $16.7 \%$ had never heard of any of the compensation strategies before. Only a small group (3.5\%) was aware of all 7 categories of compensation strategies. The median number of categories that respondents were aware of was 3. Apart from the use of walking aids and alternatives to walking, external cueing was the most widely known category of compensation strategies ( $46.9 \%$ had heard of it), followed by internal cueing (44.8\%). Action observation and motor imagery was the least known category (14.3\%). Dutch respondents from the ParkinsonNEXT cohort generally knew more categories of strategies (median 4) compared to respondents from within the Fox Insight cohort (median 3; $p<$ $0.001)$.

Most respondents had read about the strategies themselves (35.0\%), had heard about the strategy from their physical therapist $(29.6 \%)$, or had invented the strategies themselves (12.5\%). One in 3 participants $(32.2 \%)$ had ever received targeted advice from a professional focused on the use of compensation strategies for gait impairments in PD. Notably, $75.2 \%$ of respondents indicated that they would be interested to learn more about the available compensation strategies.

\section{Use of Compensation Strategies}

Of all respondents, $22.8 \%$ had never tried any form of compensation strategies before, despite experiencing clear and sometimes disabling gait impairments. Fewer than $1 \%$ of respondents had tried all 7 categories of compensation strategies. The median number of categories that respondents had ever tried was 2 . Adapting a new walking pattern was tried most often $(78.4 \%$ of respondents who were aware of it had ever tried it), followed by internal cueing $(76.8 \%)$. Alternatives to walking was the least tried category $(28.3 \%)$.

Overall, $64.7 \%$ of respondents still used $\geq 1$ compensation strategies in daily life. Compensation strategies were most often used when walking outdoors or in time-pressure situations and were least often applied when attempting to stop walking or cross a doorway. The median number of categories used in daily life was 1 . Changing the balance requirements was the most widely used category. Among the 1,729 users of this category, $429(24.8 \%)$ respondents used walking aids only, whereas $1,300(75.2 \%)$ also used other balance strategies (e.g., making a volitional weight shift to initiate gait). After changing the balance requirements, internal cueing was most often applied in daily life $(71.7 \%$ of respondents who had tried it continued to use it), followed by altering the 
mental state (70.5\%). External cueing was the least used category $(55.3 \%)$.

Among the respondents using compensation strategies, $12.4 \%$ reported that they had felt obliged to switch to different strategies over time. Most often, this was due to PD progression, rendering some strategies too difficult or dangerous to apply (e.g., riding a bicycle). Another illustrative example included switching from walking over lines pasted to the floor to using a specialized Parkinson wheeled walker that is able to project a laser line on the floor. We found no suggestion that the effect of a certain strategy tapered off over time due to habituation.

\section{Patient-Reported Efficacy of Compensation Strategies}

The patient-reported efficacy of the different categories of compensation strategies is presented in Figure 1. While most respondents reported that the application of compensation strategies positively affected their gait, not every respondent seemed to benefit from every category of strategies. When the efficacy of the strategies was averaged across contexts, changing the balance requirements had the highest success rate in improving gait (76\%), whereas external cueing showed the relatively lowest success rate $(62 \%)$.

The efficacy of compensation strategies varied greatly, depending on the context in which they were applied (Figure 2). Internal cueing, for example, seemed highly effective during gait initiation ( $73 \%$ success rate) but was deemed to be less useful when attempting to stop walking (47\%). Similarly, action observation and motor imagery could be a successful strategy when walking outdoors ( $83 \%$ success rate) but seemed to be less helpful when applied in a narrow space $(55 \%)$. In general, compensation strategies were most effective when walking outdoors ( $84 \%$ success rate) or during gait initiation (79\%). Strategies were deemed least effective during an attempt to stop walking ( $54 \%$ success rate) or cross a doorway (65\%). While reports of negative effects of compensation strategies were relatively scarce (this occurred in $\approx 3 \%$ of cases), paradoxical aggravation of gait deficits was occasionally reported in stress-inducing or dual-task situations, including time-pressure situations (6\%), walking in narrow spaces or crowded areas (7\%), and walking while talking or carrying something (7\%).

\section{Subgroup Data}

The awareness and use of compensation strategies for gait impairments in PD did not differ between subgroups based on sex, freezing status, age (cutoff 65 years), time since diagnosis (cutoff 5 years), and the ability to perform a dual task (persons with little to no difficulties vs persons with more severe difficulties). There were also no differences in the reported efficacy of different strategies between these subgroups except for a slightly higher success rate among younger patients for external cueing and adopting a new walking pattern and among persons who had little to no difficulty dual tasking for motor imagery and action observation (Table 3 ).

\section{Discussion}

A web-based survey among 4,324 persons in the Fox Insight and ParkinsonNEXT (the Netherlands) cohorts was conducted to make an inventory of patients' perceptions of compensation strategies for gait impairments in PD. The main findings of this study were as follows: (1) compensation strategies are commonly used by persons with PD and gait impairments, although their awareness of the full spectrum of available strategies is limited; (2) the patient-rated efficacy of compensation strategies is high but varies depending on the context in which they are applied; and (3) the efficacy of compensation strategies varies per person, emphasizing the need for a more personalized approach to gait rehabilitation in PD. We discuss these findings in further detail below.

Figure 1 Overall Patient-Reported Efficacy of Different Compensation Strategies for Gait Impairments in Parkinson Disease

$$
\begin{aligned}
& \text { Changing the balance requirements }(n=1,208) \\
& \text { Altering the mental state }(n=833) \\
& \qquad \text { Internal cueing }(n=861)
\end{aligned}
$$

Adapting a new walking pattern $(n=760)$

Action observation and motor imagery $(n=242)$

External cueing $(n=560)$

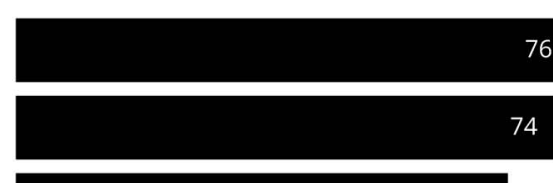

68

67

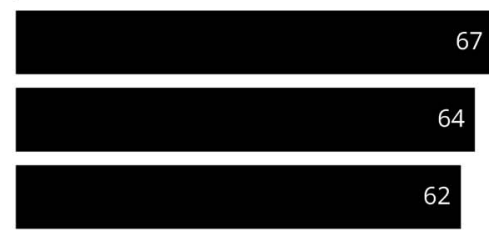

Positive effect (\%)

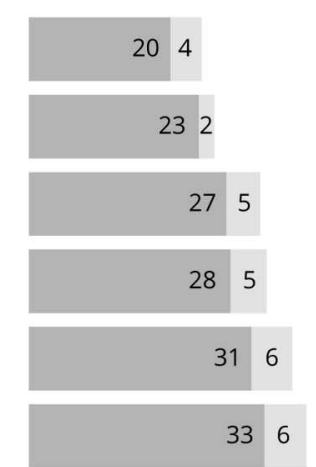

No effect/negative effect $(\%)$

Sample size represents the number of respondents who indicated that they had ever tried that specific category of strategies. Values represent the percentage of respondents experiencing a positive effect averaged across all contexts to provide an overall indication of efficacy. 
Figure 2 Patient-Reported Efficacy (Percent Indicating a Positive Effect) of Different Compensation Strategies for Gait Impairments in Parkinson Disease, Depending on the Context in Which They Were Applied
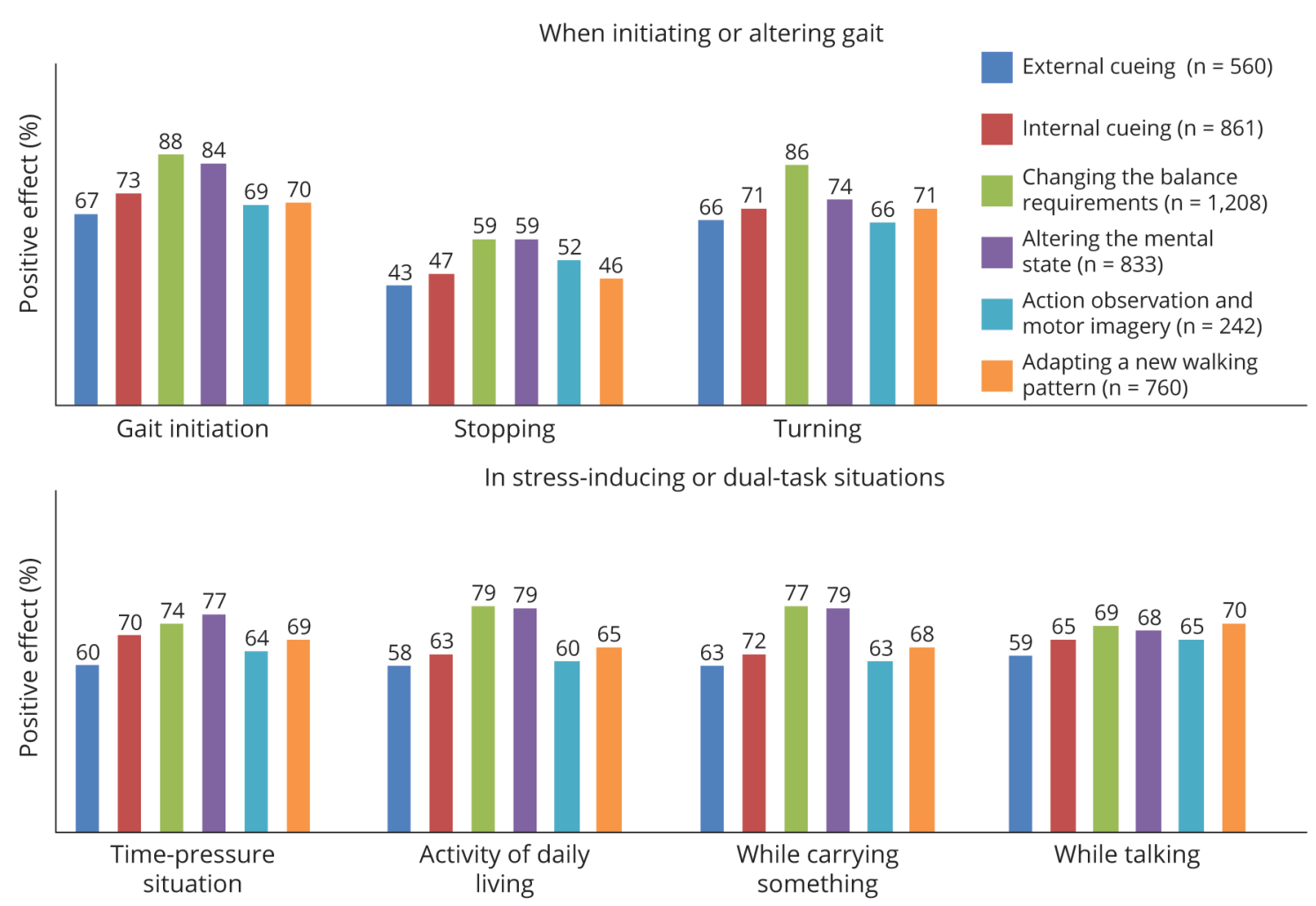

When adapting to the environment

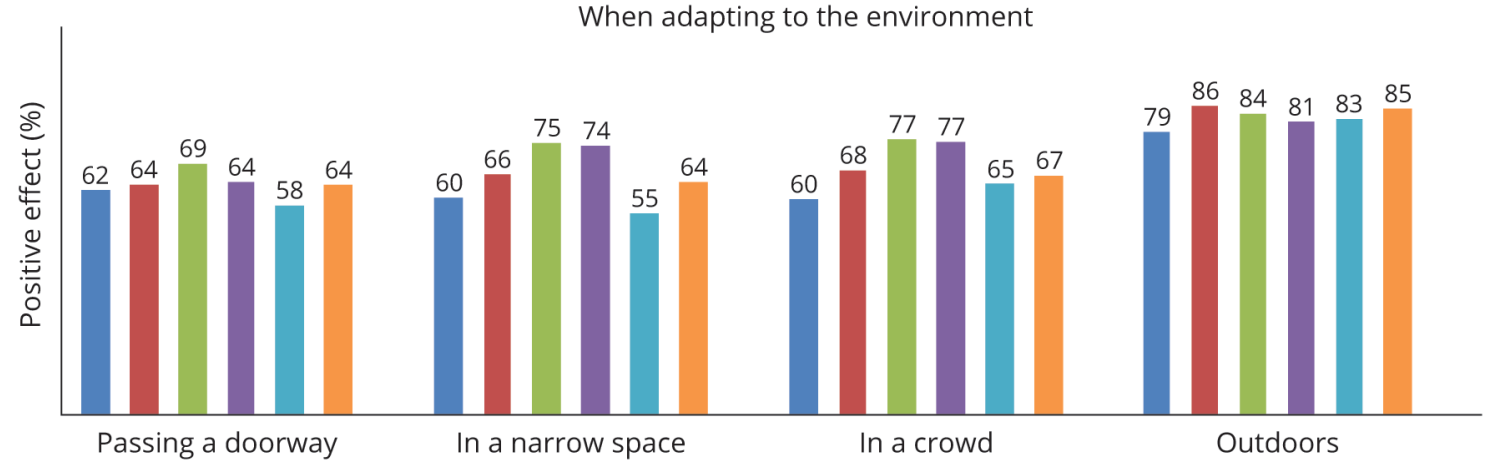

Values represent the percentage of users experiencing a positive effect on gait impairments while applying a specific strategy in a specific context.

First, considering the severity of walking difficulties that respondents expressed, we consider the awareness of the full spectrum of compensation strategies among persons with $\mathrm{PD}$ to be rather limited. The median number of known categories was 3 of 7 , and a striking 1 in 5 patients had no prior awareness of any of the compensation strategies for gait impairments. About half of the respondents had acquired this knowledge themselves through reading or personal experience. Notably, only 1 in 3 patients had ever received targeted advice from a professional, focused specifically on strategies to overcome gait impairments. Moreover, only $1 \%$ of patients had tried strategies from all 7 categories available. A previous study among health care professionals in the Netherlands demonstrated that only $23 \%$ of PD health care professionals (i.e., physiotherapists, occupational therapists) apply all 7 categories of compensation strategies in clinical practice when working with patients with PD experiencing gait impairments due to the lack of specific knowledge and skills in this field. ${ }^{19}$ Considering that PD care in the Netherlands is organized in a high-standard professional network of therapists who have received dedicated $\mathrm{PD}$-specific training and treat large numbers of patients (ParkinsonNet), ${ }^{20}$ this percentage might be an overestimation of the global knowledge and application of compensation strategies among PD health care professionals. This may also explain why Dutch respondents from ParkinsonNEXT knew more strategies than respondents from Fox Insight.

Regardless of the underlying explanations, it is evident that both persons with PD and PD health care professionals ${ }^{19}$ are 
Table 3 Subgroup-Reported Efficacy (Percent Positive Effect) of Different Compensation Strategies for Gait Impairments in PD

\begin{tabular}{|c|c|c|c|c|c|c|c|c|c|c|}
\hline & Men & Women & FOG+ & FOG - & $<65$ y old & $>65$ y old & $\begin{array}{l}<5 \text { y since } \\
\mathrm{PD} \\
\text { diagnosis }\end{array}$ & $\begin{array}{l}>5 \text { y since } \\
\text { PD } \\
\text { diagnosis }\end{array}$ & $\begin{array}{l}\text { No/little } \\
\text { difficulty dual } \\
\text { tasking }^{\text {a }}\end{array}$ & $\begin{array}{l}\text { More } \\
\text { difficulty dual } \\
\text { tasking }^{a}\end{array}$ \\
\hline External cueing $(n=560)$ & 60.2 & 63.2 & 62.4 & 58.9 & $66.4^{\mathbf{b}}$ & $59.4^{\mathbf{b}}$ & 63.0 & 61.6 & 63.3 & 59.7 \\
\hline Internal cueing $(n=861)$ & 67.0 & 68.6 & 67.8 & 66.6 & 71.9 & 65.7 & 68.5 & 67.4 & 69.5 & 68.3 \\
\hline $\begin{array}{l}\text { Changing the balance } \\
\text { requirements }(n=1,208)\end{array}$ & 73.4 & 79.3 & 76.6 & 75.1 & 76.7 & 75.9 & 77.1 & 75.4 & 78.2 & 74.6 \\
\hline $\begin{array}{l}\text { Altering the mental state } \\
(n=833)\end{array}$ & 72.7 & 76.1 & 75.9 & 71.4 & 73.5 & 74.6 & 73.6 & 74.5 & 76.3 & 72.5 \\
\hline $\begin{array}{l}\text { Action observation and } \\
\text { motor imagery }(n=242)\end{array}$ & 65.8 & 60.0 & 61.8 & 65.5 & 66.9 & 62.0 & 66.8 & 60.9 & $69.4^{d}$ & $58.8^{\mathrm{d}}$ \\
\hline $\begin{array}{l}\text { Adapting a new walking } \\
\text { pattern }(\mathrm{n}=760)\end{array}$ & 66.5 & 67.8 & 67.6 & 66.0 & $71.9^{c}$ & $65.2^{c}$ & 69.5 & 66.0 & 69.6 & 68.0 \\
\hline
\end{tabular}

Abbreviations: FOG = freezing of gait; $P D=$ Parkinson disease.

Sample sizes represent the number of respondents who indicated that they had ever tried that specific category of strategies. Values represent the percentage of respondents experiencing a positive effect averaged across all contexts to provide an overall indication of efficacy. Comparative analyses were performed with a $\chi^{2}$ test.

a Based on the Fox Insight questionnaire Your Cognition and Daily Activities: "How much difficulty do you experience doing >1 thing at a time?"

${ }^{\mathrm{b}} p=0.04$.

${ }^{c} p=0.05$.

${ }^{\mathrm{d}} p=0.01$.

interested in learning more about compensation strategies. Integrating the use of compensation strategies into educational programs or developing a dedicated online platform about the various available strategies might facilitate finding a suitable strategy for every person with PD who experiences gait impairment. This notion is underscored by the present findings showing that the application of a single strategy is often insufficient because different contexts may require different types of strategies or because individual patients simply respond better to one specific strategy compared to another. In addition, our findings show that the feasibility of a previously successful strategy may diminish over time because of progression of disability, emphasizing the need to have a broader spectrum of compensation strategies available so that a customized renewed approach can be identified for any given individual patient. In the present work, we did not investigate whether knowing more compensation strategies positively affected a person's perceived quality of life, but this could be a topic of future investigations.

Second, the overall patient-rated efficacy of compensation strategies is high across all 7 categories. While the main body of scientific work on compensation strategies has thus far focused on external cueing, perhaps because external cueing is easily controllable in a laboratory setting, ${ }^{21-24}$ it is the least effective category according to patients. Unsurprisingly, because it is the most commonly known and applied category among PD health care professionals, ${ }^{19}$ the existence of external cueing was widely known among respondents. Yet, only few patients actually applied external cues in their daily lives. In contrast, strategies changing the balance requirements and altering the mental state were deemed to be most effective and were accordingly most often used. These categories may be more accessible and feasible for persons with PD because they typically do not require specific devices (e.g., laser shoes, a metronome) or adaptations to the environment (e.g., 2- or 3dimensional patterns on the floor). They may also be preferred because they are relatively less noticeable to bystanders, avoiding stigmatization or feelings of embarrassment. ${ }^{25,26}$ Therefore, our findings reinforce the notion that all categories of compensation, not just external cueing, deserve further systematic investigation.

The effects of compensation strategies vary depending on the context in which they are applied, underlining the importance of a tailored approach to gait rehabilitation. We were struck by the relatively modest effect of compensations strategies during attempts to stop walking. More work is needed to clarify why gait termination is less influenced by the application of compensation strategies and what alternative strategies could be developed to ameliorate this.

Another notable finding was that some respondents experienced a negative effect of compensation strategies during stress-inducing or dual-task situations. In PD, gait deficits are generally exacerbated while dual tasks are performed because the need to concentrate on executing the concurrent task interferes with the patient's ability to focus purposefully on gait. ${ }^{27-29}$ Compensation strategies are believed to aid in prioritizing tasks and in allocating attention to gait. ${ }^{14}$ However, the introduction of an additional task, namely the application of a compensation strategy, might exceed the attentional resources in certain individuals, causing a paradoxical aggravation of walking difficulties instead of an improvement. ${ }^{17}$ This 
is also reflected in the present study by the slightly higher efficacy ratings of respondents with little to no difficulties with dual tasking compared to respondents with more difficulties with dual tasking.

Third, the efficacy of compensation strategies varies per person. Exploratory subgroup examinations based on age, sex, freezing status, and disease duration, however, did not demonstrate truly remarkable differences in the patientrated efficacy of the different categories of compensation strategies. In general, compensation strategies seem to be useful in all types of patients with PD, and further work is needed to investigate optimal predictors of the effects of the different types of strategies for individual patients. Ideally, this would be investigated in a prospective clinical trial in which a clinician could also examine the severity of gait impairments present and the efficacy of the different strategies could be quantified with the use of more objective measures (e.g., improvement of spatiotemporal gait parameters, including gait variability).

Our study was not without shortcomings, and some of our findings should be interpreted with caution. Participants of both cohorts may well have been a selected and rather proactive sample of the overall PD population. Although the response rate was high for a survey study, particularly in the Fox Insight cohort, respondents may have been the most informed or motivated persons with PD. In addition, we were unable to retrieve information on the main characteristics of nonresponders from within the Fox Insight sample. The selfreported nature of the survey is further reason for caution, for example, because the extent of the gait disability could not be confirmed by an independent neurologic examination. Because PD diagnosis is also self-reported, we cannot exclude the possibility that some patients in fact had a form of atypical parkinsonism, which may respond in a different way to compensation strategies than PD. At the same time, it is quite possible that persons with atypical parkinsonism will also benefit from compensation strategies, and such compensation may be particularly important for these patients because medication is generally much less effective in improving their gait impairments. Another limitation of our study is the lack of objective information about the respondents' cognitive status; cognitive deficits may impede the ability to use particular categories of compensation strategies. ${ }^{17,30}$ It is possible that a certain degree of cognitive reserve is imperative to be able to compensate for gait impairments. ${ }^{31}$ The potential effect of impaired cognition might be particularly relevant for compensation strategies that are inherently cognitive tasks such as internal cueing (e.g., counting while walking). Further studies should aim to include a more heterogeneous study population in terms of cognitive status and include more objective measures of cognition (e.g., the Mini Mental State Examination or Montreal Cognitive Assessment) to gain more insight into the interplay between cognition and the ability to compensate for gait impairment in PD.
The present findings support the application of compensation strategies for gait impairments in PD and emphasize that a one-size-fits-all approach to gait rehabilitation is inappropriate. Persons with PD should be-and wish to bemore thoroughly informed about the range of available strategies. The choice of compensation strategies should be tailored to the individual patient and to the contexts in which the strategies need to be applied. Further prospective studies are vital to further crystallize these findings and eventually incorporate them into evidence-based protocols, thus paving the way toward a more personalized approach to gait rehabilitation in PD.

\section{Acknowledgment}

The Fox Insight Study is funded by the Michael J. Fox Foundation for Parkinson's Research. The authors thank the Parkinson community for participating in this study to make this research possible. The authors also thank ParkinsonNEXT for facilitating the distribution of the survey in the Netherlands. The Center of Expertise for Parkinson \& Movement Disorders was supported by a Center of Excellence grant awarded by the Parkinson Foundation.

\section{Study Funding}

This study was supported by a ZonMW Veni grant to Dr. Nonnekes (16.196.022).

\section{Disclosure}

A.T., L.W., M.J.N., and I.H.W.M.S. report no disclosures. J.N. was supported by a ZonMW Veni (grant 16.196.022). He reports grants from ZonMW (OffRoad grant), Michael J. Fox Foundation, Ipsen Pharmaceuticals, and Gossweiler Foundation outside the submitted work. B.R.B. currently serves as editor-in-chief for the Journal of Parkinson's Disease; serves on the editorial boards of Practical Neurology and Digital Biomarkers; has received honoraria from serving on the scientific advisory board for the Critical Path Institute, Kyowa Kirin, $\mathrm{UCB}$, and Zambon; has received fees for speaking at conferences from AbbVie, Bial, GE Healthcare, Oruen, Roche, and Zambon; and has received research support from the Netherlands Organization for Scientific Research, the Michael J. Fox Foundation, Nothing Impossible, Parkinson Vereniging, the Parkinson's Foundation, Hersenstichting Nederland, Verily Life Sciences, Horizon 2020, the Topsector Life Sciences and Health, Abbvie, UCB, Yesse Technologies, and Zambon, all outside the submitted work. Go to Neurology. org/ $\mathrm{N}$ for full disclosures.

\section{Publication History}

Received by Neurology February 27, 2021. Accepted in final form July 7, 2021.

\section{References}

1. Rascol O, Perez-Lloret S, Damier P, et al., Falls in ambulatory non-demented patients with Parkinson's disease. J Neural Transm. 2015;122(10):1447-1455.

2. Almeida LRS, Valenca GT, Negreiros N, Pinto E, Oliveira- Filho J. Disability in daily activities and fear of falling are independent predictors of quality of life in people with Parkinson's disease. Mov Disord. 2014;1:S154-S155. 
3. Dionizio C, Okamoto E, Miranda C, D'Alencar M, Piemonte ME. The independence in daily living activities is the best predictor for quality of life in people with Parkinson's disease. Mov Disord. 2018;33(suppl 2):S476.

4. Mirelman A, Bonato P, Camicioli R, et al. Gait impairments in Parkinson's disease. Lancet Neurol. 2019;18(7):697-708.

5. Armstrong MJ, Okun MS. Diagnosis and treatment of Parkinson disease: a review. JAMA. 2020;323(6):548-560.

6. Ehgoetz Martens KA, Peterson DS, Almeida QJ, Lewis SJG, Hausdorff JM, Nieuwboer A. Behavioural manifestations and associated non-motor features of freezing of gait: narrative review and theoretical framework. Neurosci Biobehav Rev. 2020;116:350-364.

7. Nutt JG, Bloem BR, Giladi N, Hallett M, Horak FB, Nieuwboer A. Freezing of gait: moving forward on a mysterious clinical phenomenon. Lancet Neurol. 2011;10(8):734-744.

8. Rahman S, Griffin HJ, Quinn NP, Jahanshahi M. The factors that induce or overcome freezing of gait in Parkinson's disease. Behav Neurol. 2008;19(3):127-136.

9. Nonnekes J, Snijders AH, Nutt JG, Deuschl G, Giladi N, Bloem BR. Freezing of gait: a practical approach to management. Lancet Neurol. 2015;14(7):768-778.

10. Vorovenci RJ, Biundo R, Antonini A. Therapy-resistant symptoms in Parkinson's disease. J Neural Transm. 2016;123(1):19-30.

11. Janssen S, Soneji M, Nonnekes J, Bloem BR. A painted staircase illusion to alleviate freezing of gait in Parkinson's disease. J Neurol. 2016;263(8):1661-1662.

12. Snijders AH, Bloem BR. Cycling for freezing of gait. N Engl J Med. 2010;362(13):e46.

13. Nonnekes J, Janssen S, Bloem BR. Superficial brain stimulation to overcome freezing of gait in Parkinson disease. Neurology. 2017;88(17):1681-1682.

14. Nonnekes J, Ruzicka E, Nieuwboer A, Hallett M, Fasano A, Bloem BR. Compensation strategies for gait impairments in Parkinson disease: a review. JAMA Neurol. 2019;76(6):718-725.

15. Nieuwboer A. Cueing for freezing of gait in patients with Parkinson's disease: a rehabilitation perspective. Mov Disord. 2008;23(suppl 2):S475-S481.

16. Tosserams A, de Vries NM, Bloem BR, Nonnekes J. Multidisciplinary care to optimize functional mobility in Parkinson disease. Clin Geriatr Med. 2020;36(1):159-172.

17. Iansek R, Danoudis M, Bradfield N. Gait and cognition in Parkinson's disease: implications for rehabilitation. Rev Neurosci. 2013;24(3):293-300.

18. Nieuwboer A, Rochester L, Herman T, et al. Reliability of the New Freezing of Gait Questionnaire: agreement between patients with Parkinson's disease and their carers. Gait Posture. 2009;30(4):459-463.
19. Tosserams A, Nijkrake MJ, Sturkenboom I, Bloem BR, Nonnekes J. Perceptions of compensation strategies for gait impairments in Parkinson's disease: a survey among 320 healthcare professionals. J Parkinsons Dis. 2020;10(4):1775-1778.

20. Bloem BR, Rompen L, Vries NM, Klink A, Munneke M, Jeurissen P. ParkinsonNet: low-cost health care innovation with a systems approach from the Netherlands. Health Aff. 2017;36(11):1987-1996.

21. Gal O, Polakova K, Hoskovcova M, et al. Pavement patterns can be designed to improve gait in Parkinson's disease patients. Mov Disord. 2019;34(12):1831-1838

22. Nieuwboer A, Kwakkel G, Rochester L, et al. Cueing training in the home improve gait-related mobility in Parkinson's disease: the RESCUE trial. J Neurol Neurosurg Psychiatry. 2007;78(2):134-140.

23. Barthel C, Nonnekes J, van Helvert M, et al. The laser shoes: a new ambulatory device to alleviate freezing of gait in Parkinson disease. Neurology. 2018;90(2):e164-e171.

24. Ginis P, Nackaerts E, Nieuwboer A, Heremans E. Cueing for people with Parkinson's disease with freezing of gait: a narrative review of the state-of-the-art and novel perspectives. Ann Phys Rehabil Med. 2018;61(6):407-413.

25. Maffoni M, Giardini A, Pierobon A, Ferrazzoli D, Frazzitta G. Stigma experienced by Parkinson's disease patients: a descriptive review of qualitative studies. Parkinsons Dis. 2017;2017:7203259.

26. Angulo J, Fleury V, Peron JA, Penzenstadler L, Zullino D, Krack P. Shame in Parkinson's disease: a review. J Parkinsons Dis. 2019;9(3):489-499.

27. Rochester L, Galna B, Lord S, Burn D. The nature of dual-task interference during gait in incident Parkinson's disease. Neuroscience. 2014;265:83-94.

28. Kelly VE, Eusterbrock AJ, Shumway-Cook A. A review of dual-task walking deficits in people with Parkinson's disease: motor and cognitive contributions, mechanisms, and clinical implications. Parkinsons Dis. 2012;2012:918719.

29. de Souza Fortaleza AC, Mancini M, Carlson-Kuhta P, et al. Dual task interference on postural sway, postural transitions and gait in people with Parkinson's disease and freezing of gait. Gait Posture. 2017;56:76-81.

30. Sturkenboom I, Nott MT, Bloem BR, Chapparo C, Steultjens EMJ. Applied cognitive strategy behaviours in people with Parkinson's disease during daily activities: a crosssectional study. J Rehabil Med 2019;52(1):jrm00010.

31. Stern Y. Cognitive reserve in ageing and Alzheimer's disease. Lancet Neurol. 2012; 11(11):1006-1012 


\section{Neurology}

\section{Perception and Use of Compensation Strategies for Gait Impairment by Persons With Parkinson Disease}

Anouk Tosserams, Lisanne Wit, Ingrid H.W.M. Sturkenboom, et al.

Neurology 2021;97;e1404-e1412 Published Online before print September 8, 2021

DOI 10.1212/WNL.0000000000012633

\section{This information is current as of September 8, 2021}

Updated Information \& Services

References

Citations

Subspecialty Collections

Permissions \& Licensing

Reprints including high resolution figures, can be found at: http://n.neurology.org/content/97/14/e1404.full

This article cites 31 articles, 3 of which you can access for free at: http://n.neurology.org/content/97/14/e1404.full\#ref-list-1

This article has been cited by 1 HighWire-hosted articles: http://n.neurology.org/content/97/14/e1404.full\#\#otherarticles

This article, along with others on similar topics, appears in the following collection(s):

\section{All Rehabilitation}

http://n.neurology.org/cgi/collection/all_rehabilitation

\section{Class IV}

http://n.neurology.org/cgi/collection/class_iv

Parkinson's disease/Parkinsonism

http://n.neurology.org/cgi/collection/parkinsons_disease_parkinsonism

Information about reproducing this article in parts (figures,tables) or in its entirety can be found online at:

http://www.neurology.org/about/about_the_journal\#permissions

Information about ordering reprints can be found online:

http://n.neurology.org/subscribers/advertise

Neurology ${ }^{\circledR}$ is the official journal of the American Academy of Neurology. Published continuously since 1951, it is now a weekly with 48 issues per year. Copyright Copyright ( 2021 The Author(s). Published by Wolters Kluwer Health, Inc. on behalf of the American Academy of Neurology.. All rights reserved. Print ISSN: 0028-3878. Online ISSN: 1526-632X.

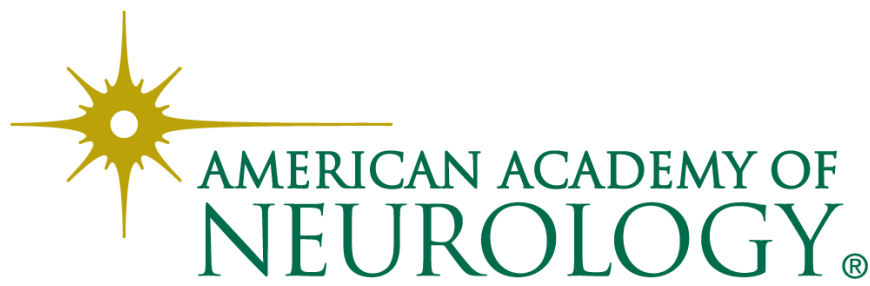

